MS. TAMAR GUY-HAIM (Orcid ID : 0000-0002-6962-0262)

DR. GIL RILOV (Orcid ID : 0000-0002-1334-4887)

Article type : Research Review

\title{
Diverse effects of invasive ecosystem engineers on marine biodiversity and ecosystem functions - a global review and meta-analysis
}

Running head: Impacts of invasive marine ecosystem engineers

Tamar Guy-Haim ${ }^{1,2^{*}}$, Devin A. Lyons ${ }^{3}$, Jonne Kotta ${ }^{4}$, Henn Ojaveer ${ }^{4}$, Ana M. Queirós ${ }^{5}$, Eva Chatzinikolaou ${ }^{6}$, Christos Arvanitidis ${ }^{6}$, Serena Como ${ }^{7}$, Paolo Magni ${ }^{7}$, Andrew J. Blight $^{8}$, Helen Orav-Kotta ${ }^{4}$, Paul J Somerfield ${ }^{5}$, Tasman P. Crowe ${ }^{3}$, Gil Rilov ${ }^{1,9^{*}}$

${ }^{1}$ National Institute of Oceanography, Israel Oceanographic and Limnological Research, Haifa, Israel

${ }^{2}$ GEOMAR, Marine Ecology, Helmholtz Centre of Ocean Research Kiel, Germany

${ }^{3}$ School of Biology \& Environmental Science, University College Dublin, Dublin, Ireland

${ }^{4}$ Estonian Marine Institute, University of Tartu, Tallinn, Estonia

${ }^{5}$ Plymouth Marine Laboratory, Plymouth, UK

${ }^{6}$ Institute of Marine Biology, Biotechnology and Aquaculture, Hellenic Centre for Marine Research, Heraklion, Greece

${ }^{7}$ Consiglio Nazionale delle Ricerche, Istituto per l'Ambiente Marino Costiero (CNR-IAMC), Torregrande, Oristano, Italy

${ }^{8}$ Scottish Oceans Institute, School of Biology, University of St Andrews, St Andrews, UK

${ }^{9}$ Marine Biology Department, The Leon H. Charney School of Marine Sciences,

University of Haifa, Mt. Carmel, Haifa, Israel

*Corresponding authors

This article has been accepted for publication and undergone full peer review but has not been through the copyediting, typesetting, pagination and proofreading process, which may lead to differences between this version and the Version of Record. Please cite this article as doi: $10.1111 / \mathrm{gcb} .14007$

This article is protected by copyright. All rights reserved. 
Correspondence: 1. Tamar Guy-Haim. GEOMAR, Helmholtz Centre of Ocean Research Kiel, Düsternbrooker Weg 20, Kiel 24105, Germany.tguy-haim@geomar.de. Office: +49 431 6004508, Mobile: +49 16 24037340. 2. Gil Rilov. Israel Oceanographic and Limnological Research, PO Box 8030 Haifa, 31080, Israel. rilovg@ocean.org.il. Office: +972 4 8565261, Mobile: +972 527500981.

Keywords: invasive; alien; ecosystem engineers; biological diversity; primary production; nutrient flux, sedimentation; decomposition; biodiversity-ecosystem functioning (BEF); systematic review

\section{Type of Paper: Research Review}

\section{ABSTRACT}

Invasive ecosystem engineers (IEE) are potentially one of the most influential types of biological invaders. They are expected to have extensive ecological impacts by altering the physical-chemical structure of ecosystems, thereby changing the rules of existence for a broad range of resident biota. To test the generality of this expectation, we used a global systematic review and meta-analysis to examine IEE effects on the abundance of individual species and communities, biodiversity (using several indices) and ecosystem functions, focusing on marine and estuarine environments. We found that IEE had a significant effect (positive and negative) in most studies testing impacts on individual species, but the overall (cumulative) effect size was small and negative. Many individual studies showed strong IEE effects on community abundance and diversity, but the direction of effects was variable, leading to statistically non-significant overall effects in most categories. In contrast, there was a strong overall effect on most ecosystem functions we examined. IEE negatively affected metabolic functions and primary production, but positively affected nutrient flux, sedimentation and decomposition. We use the results to develop a conceptual model by highlighting pathways whereby IEE impact communities and ecosystem functions, and identify several sources of research bias in the IEE-related invasion literature. Only a few of 
the studies simultaneously quantified IEE effects on community/diversity and ecosystem functions. Therefore, understanding how IEE may alter biodiversity-function relationships should be a primary focus of future studies of invasion biology. Moreover, the clear effects of IEE on ecosystem functions detected in our study suggest that scientists and environmental managers ought to examine how the effects of IEE might be manifested in the services that marine ecosystems provide to humans.

\section{INTRODUCTION}

Species invasions are perceived to be amongst the most influential human-derived impacts on Earth's ecosystems (Ehrenfeld, 2010, Primack, 1995). The term “invasive species" is frequently used to define alien or non-indigenous species (NIS, species that have spread beyond their natural biogeographical range to new regions, with human "assistance") that have or can potentially induce ecosystem-scale impacts (i.e., significant effects on community biodiversity and/or ecosystem functions, Pyšek, 1995, Ruiz \& Carlton, 2003). In the marine realm, biological invasions are a fast-growing environmental concern, fueled by increasing global trade of organisms across oceans, through hull fouling and in ballast water, via aquaculture trade, as live seafood and bait, through the aquarium trade, and through canals connecting previously separated bodies of water (Rilov \& Crooks, 2009). Although a much slower realisation of the extent and impacts of invasions in the sea has taken place, relative to those on land, the evidence for problematic marine invasions continues to mount (Molnar et al., 2008). Nonetheless, evidence of ecosystem-wide impacts of invaders is globally fragmented (Mooney \& Hobbs, 2000, Simberloff, 2011, Strayer, 2012) requiring synthesis, and particularly so in the marine environment (Thomsen et al., 2014).

This article is protected by copyright. All rights reserved. 
Invasive ecosystem engineers (hereafter "IEE"), are presumably among the most ecologically influential forms of bioinvaders affecting biodiversity and ecosystem functioning. Ecosystem engineers (also termed habitat modifiers, habitat formers or bioconstructors) are organisms that exert significant control over resource availability for other biota via modulation of the physical and chemical state of the environment (Jones et al., 1994). Such species create, destroy, and otherwise modify recipient habitats, thereby affecting resident organisms, the resources they rely on, and the abiotic stressors they experience. When they are invasive, such species have the potential to exert high impact on the receiving ecosystem (Crooks, 2009, Crooks, 2002, Hastings et al., 2007). Jones et al. (1994) distinguished between two types of ecosystem engineers based on the way in which they alter the ecosystem. Autogenic engineers alter the environment with their own bodies, forming part of the engineered habitat, whilst allogenic engineers modify the environment by transforming the physical and chemical state of living and non-living materials (or structures). Reef building corals exemplify the former, whilst beavers exemplify the latter (through altering the flow of rivers by building dams); and some species can act as both. Mussels, for example, add a complex substrate to rocky and muddy habitats, but also filter plankton, increasing water clarity, thereby facilitating macroalgal growth and associated invertebrate community (e.g. Kotta et al., 2009). By providing or modifying habitats, IEE may facilitate the presence of a greater number of species, be they native species (Rodriguez, 2006) or other invasive species (i.e. invasional meltdown, Simberloff \& Von Holle, 1999). However, they may also exacerbate abiotic conditions with potentially negative effects on community abundance and diversity.

Despite ample emphasis on ecosystem engineering in the invasion literature, much of the research has focused on quantifying biotic changes with only little attention paid to direct effects on ecosystem processes or functions, and the links between the two (e.g., Romero et 
$a l ., 2014)$. This is particularly true for terrestrial engineers, whereas effects of IEE on ecosystem functioning in aquatic habitats are better documented (Ehrenfeld 2010). In the past decade there have been several efforts to examine different aspects of the impacts of IEE. Two analyses, one focused on invasive carp and crayfish and another on dreissenid mussels, have examined the ecosystem impacts on freshwater systems (Higgins \& Vander Zanden, 2010, Matsuzaki et al., 2009). Recent meta-analyses focused specifically on the ecological impacts of invasive terrestrial plants (Vilà et al., 2011, Pyšek et al., 2012) and marine macrophytes (Maggi et al., 2015), the latter mostly testing trophic interactions. Several studies and qualitative reviews that explicitly consider marine invaders as habitat modifiers or ecosystem engineers exist (Crooks, 2009, Hastings et al., 2007, Jones et al., 2010), but we are unaware of any comprehensive attempt to investigate and quantitatively synthesize the ecosystem impacts of IEE in either terrestrial or aquatic/marine systems. Understanding the overall effects of IEE and the mechanisms that may cause variation in their impacts is an important challenge.

The present review and meta-analysis primarily investigates the current state of knowledge about the ecological impacts of IEE in the marine environment, including also brackish and transitional waters (i.e. estuaries and lagoons). Specifically, we investigated their effects on the abundance (biomass, density, cover) of individual native species, community-level abundance and biodiversity, and ecosystem functioning. The ecosystem functions considered include primary production, sedimentation (related to biotic activity), decomposition rates, nutrient levels and flux and several proxies for metabolic rates. Because the effect of IEE can be context-dependent (even for a single invader, across habitat mosaics within a system, e.g., Queirós et al., 2011), we investigated the role of ecological and methodological differences (i.e. moderators) in the reviewed studies as potential sources of context-dependency in IEE impacts. We aimed to answer two main questions: (1) how strong 
and diverse (positive $v s$. negative) is the effect of IEE on (a) the abundance of local species, (b) the local biodiversity, and (c) the different ecosystem functions?; and (2) are there general patterns in the response of an ecosystem to IEE, and can we identify important effectmoderators responsible for, or diverting from, those patterns?.

Undoubtedly, IEE can affect species in the recipient community negatively, through worsening of abiotic conditions or through interactions such as competition or predation (a non-engineering effect), or positively, through facilitation (supply of habitat or improvement of other abiotic conditions). Therefore, in this meta-analysis, setting a priori expectations (or hypotheses) as to the direction of the summary impact (overall effect size) on diversity and functions over many studies may not be relevant or possible. Nonetheless, in the case of autogenic IEE, we may expect an overall positive effect on abundance and diversity indices. This is because in many cases such IEE add niches for the local species pool by transforming a structurally-simple seascape into a more complex one (i.e., facilitation), while the negative effects mediated through competition (or trophic interactions) might be expected to impact fewer local species (Stachowicz 2001, Bruno et al. 2003). In contrast, community functions can be either positively or negatively affected depending on the dominant functional group that is impacted by the IEE (e.g., autotrophs, carnivores, etc.). We therefore offer a primary hypothesis suggesting that community indices, on average, will be positively impacted by IEE, if the majority of studies investigated are autogenic IEE, while impacts on functions will be individually (per study) strong but with no clear overall direction.

In addition to differing by engineering type (autogenic or allogenic), the effect of IEE may differ between habitat types and regions. Jones et al. (1997) suggested that engineering processes are more important under extreme conditions than in benign environments. Among marine ecosystems, intertidal habitats experience more extreme conditions (both desiccation and wave action). Thus, we predict that the magnitude of IEE effects in these naturally 
stressful habitats will be larger than in constantly submerged habitats. Romero et al. (2014) found that ecosystem engineers at lower latitudes $\left(<23^{\circ}\right)$ had larger (positive) effect on species richness than at higher latitudes. They posited that this was the result of the stronger density-dependent interactions (predation, parasitism, competition) prevailing in tropical regions (Schemske et al., 2009); the rational is, that by forming new habitats, autogenic engineers provide a greater advantage to tropical communities. Accordingly, we also predict that the magnitude of IEE effects in lower latitudinal regions will be greater.

\section{MATERIALS AND METHODS}

This study is guided by a rigorous protocol (Rilov et al., 2012) for the systematic review of literature that adopted a Structured Systematic Review procedure, as suggested by the Collaboration for Environmental Evidence (CEE, http://www.environmentalevidence.org/). This method was chosen as it provides an objective, transparent and repeatable methodology with which to review and critically assess literature. The final review was conducted during 2016-2017.

\section{Data Collection and Eligibility Criteria}

An initial literature search was performed on 18 March 2012 on the Web of Science and Scopus online databases. A complementary, updated, search was carried out on 10 January 2017 on the above mentioned databases. We used the search criteria described in Rilov et al. (2012), and the comprehensive search terms list can be found in Appendix S1 (Supporting Information). The eligibility of the studies for final analysis was assessed via an agreed set of inclusion criteria at three levels: title, abstract and full-text. Eligible studies included: i) an exposure (an engineering effect by an invasive species); ii) an examination of a relevant population or community that was part of a marine or brackish water ecosystem; iii) a relevant comparison (i.e. an experimental or observational comparison between areas or 
time points with and without IEE); and iv) a relevant outcome (a measure of ecosystem structure or functioning), as defined here. Studies that contained only non-empirical data (e.g., theoretical and numerical modelling studies) or that did not correspond to the specified structure were excluded from further analysis. Redundant studies that used the same data in different publications were eliminated, preventing double-counting. Studies for which abstracts matched the inclusion criteria were further analysed at full text, or otherwise excluded. The degree of agreement between reviewers $(n=14)$ on the application of eligibility criteria was determined by calculation of Fleiss' Kappa inter-rater agreement test (R Core Team 2012, package 'irr') using a common subset of references $(n=60)$. The degree of agreement on inclusion and exclusion of studies in the list between reviewers was satisfactory at a kappa $=0.56, p<0.001$, which was reached after a first round of reviews of a first subset of references, discussion and clarification of criteria against particular studies.

Additional eligibility criteria were applied at full text level review. First, the reported effect was required to meet the 'ecosystem engineering' definition (Hastings et al., 2007), i.e. including abiotic and biotic modification components. Secondly, eligible studies reported on at least one of the following outcomes: 1) single species abundance; 2) community abundance (pooled biomass or total number of individuals); 3) species richness; 4) species diversity (Shannon index); 5) community evenness (Pielou's index); 6) primary production (chlorophyll $a$ concentration); 7) sedimentation; 8) decomposition; 9) nutrient cycling (levels and fluxes); 9) growth and metabolic functions. Thirdly, we excluded studies that failed to provide the set of parameters required for the calculation of the effect size (Hedges' $\mathrm{g}$ ): averages, sample sizes and variance, estimated both with and without the IEE. The screening process resulted in a final set of references, some of which contained data on multiple outcomes. In such cases, each outcome was used as an independent dataset (hereafter, a 'study').

This article is protected by copyright. All rights reserved. 


\section{Data Extraction and Effect Size Calculation}

Means, sample sizes and variance estimators were extracted directly from reviewed manuscripts, including text, tables and figures. In the latter case, image analysis software ImageJ (https://imagej.net/) and DataThief III (http://datathief.org/) were used. Rates and fluxes (nutrients and metabolic rates) were standardised to obtain a common direction - that is, in the case of benthic-pelagic nutrient flux, we considered efflux from the sediment as a positive flux, and for metabolic functions, we focused on rates measured on the native species or community. The assessment of primary production was based on Chlorophyll $a$ measurements in the sediment and water column, and therefore did not include the direct effect of the IEE on production. For multi-factorial experimental designs, factor information was recorded. Potential moderators, i.e., factors that may modify the effect of the analysed IEE species were recorded for each study, and considered in subsequent analyses (see below). Hedges' $g$ (Hedges, 1981), the unbiased mean difference, was used as the effect size estimator. This statistic estimates the difference in the response variable between the 'treatment' (IEE present) and control (IEE absent) groups, standardized by the within-group standard deviation (see formulae in Appendix S2), and assigning more weight to studies where variances are small, and/or the number of observations used to calculate means is large. This common metric enables the calculation of summary (overall) effects across data that may have been captured on different scales (Borenstein et al., 2011). Effect sizes for matched (paired) groups or pre-post designs (e.g., BACI) were adjusted using the intra-class correlation coefficient (ICC) (Wolak et al., 2012). When the full text did not provide sufficient information to calculate ICC, this was assumed to be 0.5 , thus allowing for a narrower variance within study than in non-correlated studies $(\mathrm{ICC}=0.0)$, and wider than perfectly correlated ones $(\mathrm{ICC}=1.0)$. Studies often reported on time-series data for the same sampled population (i.e. repeated measurements designs). Because the effect of an invasive 
species may fluctuate over time, depending on various environmental factors (Harlin \& Villalard-Bohnsack, 2001) and food-web interactions (Nyström et al., 2001), when the timeseries of the measured effect was accompanied with a congruent time-series of the predictor (invasive ecosystem engineer species abundance), we selected two time-points for analysis: the time-point of the maximal IEE abundance (treatment group), and the latest time-point of minimum abundance or absence (control group). When there was no information regarding the IEE abundance, we averaged the effect size by use of fixed-effect model structure for summary effect calculation (Borenstein et al., 2011). Similarly, dependent subgroups within a study, such as different measures for the same outcome, different sites or multiple levels within treatment and control groups, were averaged using the fixed-effect model. Multiple independent experiments or publications that included the effect of multiple IEE species were analysed as independent studies.

\section{Meta-Analysis}

The effect size estimates from individual studies were aggregated using the software Comprehensive Meta-Analysis v.2.2.064 (Borenstein et al., 2005). A random-effects metaanalysis model was used to calculate summary effects and confidence intervals (i.e. across studies) because within an outcome category, different designs, target populations, measurement protocols, and experimental characteristics were included, making the outcomes heterogeneous (Borenstein et al., 2011). Within each category, we interpreted asymmetrical funnel plots to detect publication bias. Assuming that studies with small sample size and small to non-significant effect size are at a greater risk of not being published, publication bias is expected to decrease as the sample size goes up. In the funnel plot, large studies appear towards the top of the graph and smaller studies appear towards the bottom. Asymmetry around the mean effect size may indicate bias. The iterative algorithm Trim and Fill (Duval \& Tweedie, 2000) was also used to evaluate publication bias. 


\section{Moderator Analyses}

Study-level covariates may contribute to effect size variation and can thus be regarded as potential effect moderators. These covariates can be related to either the characteristics of the studied species/habitats/regions or the study itself (e.g., methodology used). For each outcome category, we defined six possible moderators, which divided outcome types into pre-ordained subgroups based on: engineering type; study type; study setting; the taxonomic attribution of the IEE; habitat and geographic region. Engineering type included three subgroups: autogenic, allogenic, or both. We used two methodological moderators: study type, i.e. observational vs. experimental studies (where manipulative procedures associated with the IEE were carried out); and the study setting, i.e. field $v s$. laboratory. The taxonomic division or phylum was assigned to the IEE taxonomic attribution. Study region was categorized based on the Large Marine Ecosystems defined by Sherman \& Hempel (2009).

The relationship between potential effect moderators and the effect size within each outcome category was assessed via subgroup analyses using a mixed-effects model structure. This model applies a random-effects model within subgroups and a fixed-effect model across subgroups to compute the overall (summary) effect, allowing for tests of heterogeneity as well as for tests of random effects models once the variability accounted for by moderator variables has been removed (Lipsey \& Wilson, 2001).

This article is protected by copyright. All rights reserved. 


\section{RESULTS}

Our literature search yielded 3737 publications. Of these, 1846 were excluded at title level, and 1537 were further excluded at abstract level. Of the 354 references retained, 215 were excluded after full-text assessment (see Appendix S3 for justifications of the outcomes of each assessment). A total of 384 studies from which effect size could be calculated were extracted from the remaining 139 references. From these, all but five of the included papers were published after the year 2000 (Fig. 1), most likely reflecting the increasing global trend in quantitative studies on impacts of non-indigenous species (Hulme et al., 2013).

\section{Study and data characteristics}

The majority of the references included in the final analysis (52\%) did not explicitly use the term "ecosystem engineer" or its common synonyms (e.g., habitat-modifier, bioconstructor) to describe the effect type of the invasive species. In those cases, ecosystem engineering effects were inferred at the level of full-text analysis, based on the study context. 55\% of the studies reviewed were observational (Fig. S1). These included before-after designs, and comparisons between multiple sites. The vast majority of the studies (93\%) were conducted in the field, and the rest were conducted in the laboratory. $51 \%$ of the studies described an autogenic effect, $26 \%$ an allogenic effect, and 23\% described combined effects (see Fig. S1). $59 \%$ of the IEE species in the studies analysed were primary producers (Fig. 2), including seaweeds (algae), grasses (seagrasses and saltmarsh plants) and mangroves. Of the rest, the most prominent groups were bivalves (21\%) and worms (12\%). The most studied species were the Pacific oyster Magallana gigas (formerly Crassostrea gigas) and the cordgrasses Spartina alterniflora and S. townsendii var. anglica.

Reviewed studies (Fig. 2) most frequently investigated rocky intertidal habitats (20\%), followed by sandflats (14\%), mudflats, lagoons and estuaries (10-12\% each). The study regions included the coasts and estuaries of all continents except Antarctica (Fig. 3), 
with an apparent bias towards the Mediterranean Sea (15\%) and California Current (14\%), followed by the Celtic-Biscay Shelf (9\%), the North Sea (8\%), the Southeast Australian Shelf $(8 \%)$ and the Baltic Sea (7\%). There were over 10 times more studies in high latitude regions than in low latitude $\left(<23^{\circ}\right)$ regions.

The majority of studies included outcomes covering abundance categories (single species abundance, $21 \%$; community abundance, 19\%; species richness, 14\%), whereas studies related to ecosystem functions were less numerous (4-6\% for each category, except 14\% for nutrient fluxes, Fig. 4). Of the 139 papers from which data were extracted, only 18 reported effects on both community structure and some form of ecosystem functions, and 20 reported effects on single species and ecosystem function (Appendix S4). Of these, very few reported results on the same or similar ecosystem functions, limiting our ability to directly compare the relationships (negative or positive) between community or single species responses, and ecosystem functions across studies in an IEE context.

\section{Overall outcomes}

None of the five abundance/diversity outcome categories had an overall (cumulative) significant effect size (or impact of IEE). Significant and strong/clear overall effects were identified for four out of the five ecosystem functions analysed (sedimentation, decomposition, nutrient cycling, and growth and metabolic rates). Negative mean effects were detected in four of the ten categories tested, three were positive and three were near neutral (Fig. 4, effect sizes are reported as Hedges' g $\pm 95 \%$ C.I, hereafter). A detailed description and figures of the findings at the individual outcome categories are given in Appendix S5 in the Supporting Information. We proceed by describing only the most noteworthy of those findings, and show only significant and possibly meaningful subgroup results.

This article is protected by copyright. All rights reserved. 


\section{Single-Species Abundance}

Although 49 of the 82 individual effect sizes were statistically significant (27 were negative and 22 positive), the overall effect of the presence of IEE on single species abundance was negative but relatively small but not significant $(\mathrm{g}=-0.163 \pm 0.172, p=0.062$, Fig. 4 , see Fig. $\mathrm{S} 2$ for forest plot results per study and S3 for full subgroup analysis). Among habitat types (Fig. 5A), IEE had statistically significant positive overall effect in a coral reef study $(\mathrm{g}=3.445 \pm 2.555, p=0.008)$ and significant negative summary effect in a harbor study $(\mathrm{g}=-$ $0.405 \pm 0.405, p=0.05)$. Of the 23 studied regions, IEE had significant effects only in three: negative in the Iberian Coastal region $(p=0.004)$ and in the Southeast Australian Shelf $(p=0.042)$; and had a positive effect in the Southeast U.S. Continental Shelf ( $p=0.003$, Fig. 5B). No differences were found between study types, engineering types, and IEE taxonomic groups in their overall effects, and none of the individual subgroup effects were statistically significant (Fig. S3)

\section{Community Abundance}

41 out of 74 individual effect sizes in the analyses of IEE on community abundance were statistically significant (some with very strong effects); of these, 21 were negative and 20 positive, and the overall effect size was small and non-significant $(\mathrm{g}=0.039 \pm 0.191, p=0.687$, Fig. 4, see Fig. S4 for forest plot results per study and S5 for full subgroup analysis). Of the engineering types, only the combined engineering type (autogenic as well allogenic engineering species) had a significant negative effect (Fig. 5C). Chlorophyta was the only taxonomic group identified as causing significant (negative) effect (Fig. 5D). In the Bay of Bengal and in the Celtic-Biscay Shelf there were positive significant effects of IEE, whilst in the Mediterranean their effect was negative (Fig. 5E). No differences were found between study types and habitat types in their overall effects, and none of the individual subgroup effects were statistically significant. 


\section{Species Richness}

Thirty-three out of the 55 studies assessing the effects of IEE on species richness led to significant effect sizes, 18 negative and 15 positive; the resulting overall test was therefore non-significant ( $g=0.059 \pm 0.264, p=0.662$, Fig. 4, Fig. S6). This heterogeneity could not be explained by study type, study setting or engineering type in the subgroup analysis (Fig. S7).

Of the taxonomic groups assessed, only Bivalvia had a significant (positive) effect on species richness (Fig. 5F). Mudflats were the only habitat where significant (positive) effect sizes were observed (Fig 5G). Significant positive effect sizes were observed for studies done in the Celtic-Biscay Shelf and the Gulf of California and in the Mediterranean and the Caribbean Sea significant effects were negative (Fig. 5H).

\section{Species Diversity}

Only ten of 31 individual effect sizes were statistically significant (4 negative and 6 positive), leading to a small and non-significant overall summary effect $(\mathrm{g}=-0.050 \pm 0.318, p=0.760$, Fig.4, see Fig. S8). This heterogeneity could not be explained by the subgroup analyses as almost none of the analyses were significant (see Fig. S9). Lagoons were the only habitat where significant (negative) effect sizes were observed (Fig. 5I). Of the 12 study regions, an overall significant effect was found only for the Mediterranean where impacts were strongly negative (Fig. 5J).

\section{Community Evenness}

Only four of the 12 individual effects on evenness were significant, 2 positive and 2 negative, leading to an overall small non-significant negative effect ( $\mathrm{g}=-0.238 \pm 0.517, p=0.367$, Fig.4, see Fig. S10). None of the subgroup analyses could explain the heterogeneity in these studies (Fig. S11).

This article is protected by copyright. All rights reserved. 


\section{Primary Production}

The summary effect of IEE on primary production was non-significant $(g=-0.153 \pm 0.484$, $p=0.535$, Fig. 4). Eleven of 15 individual effect sizes were statistically significant; six of these were negative and the rest positive (see Fig. S12). This heterogeneity could not be explained by the subgroup analyses as almost none of the analyses were significant (see Fig. S13). The only significant effect was obtained in the analysis of IEE taxonomic groups, where Rhodophyta had a significant positive effect (Fig. 5K).

\section{Sedimentation rate}

Ten out of the 21 studies assessing the effects of IEE on sedimentation rate led to significant effect sizes, 4 negative and 6 positive; the resulting overall test was positive and significant $(g=0.997 \pm 0.757, p=0.010$, Fig. 4, Fig. S14). Only the observational studies showed significant (positive) effects (Fig. 5L). Rocky intertidal and cobble beach habitats had significant (positive) effect sizes (Fig 5M). Of the 12 study regions, an overall significant effect was found only for the Gulf of Alaska where impacts were strongly positive (Fig. 5N). Angiospermae was the only taxonomic group identified as causing significant (positive) effect (Fig. 5O).

\section{Decomposition}

IEE had an overall positive and significant effect on decomposition $(\mathrm{g}=0.469 \pm 0.451$, $p=0.041$, Fig. 4). Seven of the 16 associated individual effect sizes were statistically significant, six were positive and one negative (Fig. S16). Moderator analyses failed to show significant differences between different subgroups (Fig. S17).

\section{Nutrient flux}

IEE caused a significant positive summary effect on nutrient levels or fluxes ( $g=0.811 \pm 0.268$, $p<0.001$, Fig. 4). Thirty-four of the 53 associated individual effect sizes were significant, seven of these negative and 27 positive (Fig. S18). The effect of IEE on all nutrient types was 
positive, except for a negative non-significant effect on sulphur flux. The (positive) effects on the fluxes of organic carbon, organic and inorganic nitrogen and inorganic phosphorus were significant (Fig. 5P). Both observational and experimental studies revealed significant positive effects of IEE (Fig. S19). Allogenic engineers had a strong significant positive effect on nutrient fluxes while the effect of autogenic engineers was smaller and non-significant (Fig. 5Q, Fig. S19). Of the seven IEE taxonomic groups, five had significant positive effects on nutrient fluxes: Angiosperms, Annelida, Bivalvia, Ctenophora, and Gastropoda (Fig. 5R). The (positive) effect of IEE on nutrient flux was found in most studied habitats (Fig. 5S). Of the studied regions (Fig. 5T), positive significant effects $(p<0.001)$ were found for the Baltic Sea, Caspian Sea, East China Sea, Celtic-Biscay Shelf, Insular Pacific-Hawaiian, and Southeast Australian Shelf.

\section{Growth and metabolic functions}

The presence of IEE caused an overall significant negative effect on metabolic functions ( $\mathrm{g}=-$ $0.470 \pm 0.318, p=0.004$, Fig. 4). Sixteen of 25 individual effects were significant, 13 negative and three positive (Fig. S20). Study type analysis revealed that experimental studies found a significant negative effect on community metabolic functions while the effect detected in observational studies was small and non-significant (Fig. 5U). Both autogenic and allogenic effects were negative and very similar in size, while combined autogenic-allogenic engineers had a non-significant effect overall (Fig. S21). Habitat analysis revealed a significant negative effect of IEE in rocky intertidal habitats (Fig. 5V). Of the nine IEE taxonomic groups, three had significant positive effects on nutrient fluxes: Bivalvia, Crustacea and Gastropoda (Fig. 5W). Regional analysis did not reveal any significant effects (Fig. S21).

This article is protected by copyright. All rights reserved. 


\section{Publication Bias}

The funnel plots for the relationship between the moderator subgroups effect size and standard error were not asymmetrical (Fig. S22). Furthermore, the adjusted effect sizes, calculated using the trim-and-fill method, were not substantially different from the initial estimates, indicating the absence of significant publication bias.

\section{DISCUSSION}

This systematic review offers the first quantitative global synthesis of the effects of IEE on both biodiversity and ecosystem functions. Significant effects were found in 33-73\% of the studies, depending on the response category, $58 \%$ in studies focused on functions (combined), and $48 \%$ in those focused on biodiversity. This finding indicates that, as expected by definition, IEE often have a considerable ecological effect on the local community and its functions. However, the overall effect sizes were diverse, contrasting with our primary hypothesis. Although the majority $(74 \%)$ of the studies described an autogenic effect or had combined autogenic and allogenic effects, the overall effect sizes in the abundance/biodiversity response categories were mostly small and/or non-significant (we expected a net positive effect), whereas most overall effects of ecosystem functions were strong and significant (and not lacking an overall direction as hypothesized).

The review reveals that the scientific interest in the impacts that IEE exert on communities and functions in marine systems has greatly increased in the past two decades, since the term "ecosystem engineering" was coined by Jones et al. (1994). Studies from a large variety of species, habitats and regions around the globe, retrieved and analysed here, provide a broad and robust basis for our findings. Extensive biogeographic, taxonomic and habitat biases were present, in line with the general aquatic invasion impact literature (Thomsen et al., 2014), and a striking majority of studies was focused on IEE species that are 
primary producers. This bias is perhaps natural, as primary producers are conspicuous engineers and successful invaders, and therefore a sensible focus of study. It may also be related to the identified habitat bias. Studies of tidal sandflats and rocky intertidal areas dominate our dataset and these habitats are dominated by macro primary produces. Thus, caution is needed in the generalization of some of our findings.

We found that few studies investigated IEE impacts on community/diversity and ecosystem functions simultaneously in the same study system. In the past two decades, research on the relationship between biodiversity and ecosystem functions (BEF) has been a focus of ecology, with heated debates around theory, models and empirical evidence linking the two (Connolly et al., 2013, Hooper et al., 2005, Loreau et al., 2001, Schwartz et al., 2000, Zavaleta et al., 2010). Studies on this link in the context of ecosystem resilience or stability have also emerged, although the mechanisms are still poorly understood (Hooper et al., 2005, Loreau \& Mazancourt, 2013). Improved understanding of such relationships has become an urgent need, due to the magnitude and speed of human-induced changes to the environment through direct impacts on biota, and thus biodiversity (Gamfeldt et al., 2013, Kremen, 2005). This is especially true in the context of bioinvasions, and even more so for IEE which can have large impacts on both diversity and functions, and thus ecosystem services (following the conceptual framework in Byers et al., 2006). In light of the current findings, we encourage future studies to test the effects of IEE on diversity and functions simultaneously (perhaps considering multi-functionality, Mouillot et al., 2011) to allow the disentanglement of possible mechanisms of impact.

The subgroup analyses were not as informative as we hoped. Regarding engineer type, far fewer studies in this review assessed the impacts of invaders as allogenic engineers, probably because these are usually less obviously identifiable, and their effects are harder to determine and measure. Overall we did not identify striking differences in response to 
autogenic $v s$. allogenic engineers. In the few cases where we did identify differences, allogenic effects were generally non-significant while autogenic effects tended to be significant and negative, suggesting perhaps that autogenic effects are stronger or more consistent. An exception was the nutrient flux analysis, where allogenic IEE had a strong and significant positive effect, while the autogenic effect was weakly positive and nonsignificant. This may be explained by the fact that allogenic species can directly affect biogeochemical cycles in a habitat (for example, secretion of mucus by the ctenophore Mnemiopsis leidyi, Nasrollahzadeh et al., 2008a, 2008b). The low number of studies per subgroup when the data were divided by biogeography and habitat type resulted in low power for testing the influence of these variables on the impact of IEE. Similarly, no outstanding patterns were revealed in the analyses assessing the effect of study setting or methods.

Our analysis revealed an important contrast in the variety of outcomes caused by the presence of IEE. The overall effect of IEE on individual species was small and negative, it was non-significant in all abundance and biodiversity indices responses, but was significant for all but one of the ecosystem functions assessed. This is especially surprising given that far fewer studies focusing on functions were found (and thus greater variance could be expected), and that multiple functional parameters were aggregated for analysis within each category. The rejection of our hypothesis reflects the fact that while biological entities exhibited large variability in responses to the presence of IEE (leading to non-significant overall effects), functions appeared to be impacted more consistently (leading to significant overall effects). This variability in biotic responses is because some species within communities may be facilitated by the IEE, while others may be suppressed directly by the invader, or indirectly through trophic cascades (Grosholz \& Ruiz, 2009, Rilov, 2009). Overall, these potentially strong, individual effects may thus cancel each other out when measured at the community level, as seen here in the diversity indices and community 
biomass. Hence, quantifying effects on how the specific components of diversity change between impacted and non-impacted communities (e.g. $\beta$ diversity) may be a better path to elucidate mechanisms of impact for IEE than community level measurements alone.

\section{Species and community impacts}

Our findings are not consistent with the results of the meta-analysis by Romero et al. (2014) that found an overall positive and significant effect of ecosystem engineers on species richness in both terrestrial and aquatic ecosystems, while we found that IEE had nonsignificant overall effect on richness. However, in a further subgroup analysis, Romero et al. found that only native invertebrate engineers led to increased species richness. Possibly, in the case of IEE, the positive engineering facilitative effects are "masked" by the negative non-engineering or allogenic effects of the invasive species (because they are novel entities in the recipient environment), leading to an overall small and non-significant effect on richness. Moreover, the near-zero, overall effect on community parameters is not a true representation of the real effects of IEE. Conversely, they illustrate the complex nature of the interactions between the IEE and the different components of the invaded community. This is nicely exemplified by Neira et al. (2007), one of the studies included in this meta-analysis, where varied effects were observed in response to the invasive Spartina cordgrass across single species and taxonomic groups (Fig. 6). In the same study, the importance of the context of comparison between invaded and un-invaded areas also stands out, highlighting how comparing a mature invasion to either pre-invasion and post-invasion areas can result in very different outcomes.

Opposing effect sizes (negative and positive) of individual studies within species- and community-level outcomes are not surprising, as the strength and direction of the effect of IEE can be highly context-dependent. The subgroup analyses aimed to test whether some well-defined categories were likely to influence the strength and direction of the effects, and 
to help explain this plethora of responses. However, many subgroups considered here, particularly within the subgroup categories region, habitat type, and IEE taxonomic group, included only a small number of studies, which may have hindered our ability to discriminate those differences adequately. Here, we highlight some comparisons for which sufficient data were found, and of ecological interest.

Within taxonomic groups, macrophytic IEE were found to have overall negative effects on several outcomes. Rhodophyta had clear negative effects on single species abundance, and Chlorophyta had negative effects on single species, community abundance and biodiversity. Bivalvia had, on the other hand, positive effects on species richness (see below). The negative effects of the seaweeds were, in most cases, apparently caused by smothering or reduction of irradiance to the native flora. For example, the rhodophyte Lophocladia lallemandii is an epiphyte on the seagrass Posidonia oceanica and it was suggested that by reducing light availability, the former leads to a decrease in the growth of the native seagrass (Sureda et al., 2008). However, L. lallemandii may also negatively affect the biota associated with the seagrass (bryozoans), possibly by reducing settlement surface area and changing the flow regime that could reduce food supply to the epiphytic bryozoan (Deudero et al., 2010). In the case of the highly invasive red alga, Gracilaria vermiculophylla, its impacts on the seagrass Zostera marina were only detected in combination with increased temperature (Höffle et al., 2011), highlighting the contextdependency of the effect itself. The invasion of Caulerpa racemosa was suggested to impact community abundance through a decline in the density of infaunal bivalve molluscs and an increase of mobile epibenthic forms, possibly due to the influence of the invader on sediment properties (Lorenti et al., 2011). The effect of macrophytic IEE on the primary production of the community was mostly negative and non-significant, although a positive effect could be expected from an increased autotrophic biomass. This can be explained by the fact that the 
measured primary production proxy in these studies was chlorophyll a concentrations (in the sediment or in the water column), and therefore the biomass of the IEE itself was not included in the analysis.

In contrast to macrophytes, bivalves function both as autogenic and allogenic engineers. They can facilitate many animal groups in formerly structure-poor habitats, such as mudflats, by providing more complex attachment substratum (e.g. oysters, Lejart \& Hily, 2011). Some species of mussels further stabilize sediments (e.g. Arcuatula senhousia in southern California, Crooks, 1998); others enhance sediment de-stabilization, promoting amelioration of sediment properties via increased exchange of solutes and particles, at and below the sediment water interface (Queirós et al., 2011). These mainly facilitative effects may explain the increases in diversity caused by bivalve IEE identified in the present analysis.

Following the suggestion of Jones et al. (1997) that ecosystem engineering in harsh environments is more important than in benign environments because they can have a greater role in enhancing survival of associated species in extreme environments, our working hypothesis suggested that the effects of IEE in intertidal habitats (stressful, extreme) are greater than in submerged habitats (more benign). Furthermore, according to the 'stressgradient-hypothesis' (Bertness \& Callaway, 1994), interactions shift from negative (e.g., competition) to positive (e.g., facilitation) with increased environmental stress. Therefore, we hypothesized that in the intertidal the impacts of IEE would be positive. In terrestrial habitats, Romero et al. (2014) found that the overall effect of ecosystem engineers on species richness was indeed greater in deserts than in forests, savannas, and grassland, and explained this by the low productivity (i.e., stressful environment) of deserts, in which engineering activity is likely to promote patches with higher productivity. In their analysis, most engineering species in the desert were bioturbators (porcupines, kangaroo rats, gophers and ants) that facilitated 
the proliferation of plants. Contrary to our hypothesis, and the findings of Romero et al. (2014), we found that the effects of IEE in intertidal habitats were not greater than in submerged habitats. In our analysis, plants (seaweeds and seagrasses) constituted the majority of studied IEE species in both intertidal and subtidal habitats that may be expected to have similar effects on community productivity.

Like Romero et al. (2014) we also found that ecosystem engineering studies in tropical, low latitude regions are underrepresented. This bias may reflect the overrepresentation of ecological studies in developed countries (Martin et al., 2012, Pyšek et $a l ., 2008$ ), or a true geographical gradient, where alien species are rarer in tropical than temperate regions, either because of fewer introductions or because of exclusion by biotic pressure (Sax, 2001). One prominent regional result in our analysis was that in the Mediterranean Sea studies on IEE effects yielded only negative and mostly significant overall effects, whereas in other regions they showed inconsistent direction and non-significant effects. The Mediterranean Sea is one of the world's greatest bioinvasion "hotspots" (Rilov \& Galil, 2009), with many incoming species considered as harmful (Molnar et al., 2008). Yet, other known bioinvasion hotspots, such as the California Current ecoregion, did not show a similar trend. Many of the alien species in Mediterranean Sea are Lessepsian species, originating in the warmer Red Sea, and are thus pre-adapted to the currently increasing seawater temperature (Marras et al., 2015). It is possible that under these changing conditions IEEs in the Mediterranean Sea can suppress the less resistant, native species, rather than facilitate them. In addition, the Mediterranean Sea is oligotrophic and poor in resources (Coll et al., 2010) and, by competing for scarce resources, IEE in that area may induce more negative effects.

This article is protected by copyright. All rights reserved. 


\section{Ecosystem function impacts}

Decomposition and sedimentation rates and nutrient fluxes were positively impacted

by IEE, overall. By contrast, growth and metabolic rates significantly decreased in the presence of IEE. These findings corroborate the general expectation that IEE are high impact species, more so than other invaders, because they modify impacted habitats not only through changes in species composition and interactions but also through direct effect on ecosystem functioning. The fact that there was a consistent directional impact on most of the tested functions is not trivial given the variety of pathways by which an IEE can impact an ecosystem. The reason may be that most of the studies focused on sessile primary produces or invertebrates. Moderator effects affecting ecosystem functioning were also more apparent than those affecting variables of community indices.

Based on these finding, we propose a conceptual model with generic pathways that summarize the key processes that we think explain the IEE impacts on functions revealed in this review (Fig. 7). These may mostly be relevant to invasive primary producers and epibenthic sessile invertebrates (i.e., non-burrowing or bioturbators). These taxa normally add (or replace) 3D structure at and above the sediment-water interface in their invaded environment and thereby affect the community and functions via four interconnected pathways that are well described in the marine primary producers and bivalve ecological literature (but usually not in that of invasive species).

Pathway 1 - Reduced currents (autogenic). The erect or complex structure of the invader changes the hydrodynamic flow through the system, normally slowing currents near the bottom (e.g. Bos et al., 2007, Bouma et al., 2005). Higher deposition of particles may occur, resulting in increased nutrient fluxes due to enhanced transport of solutes and particles from the overlying water column to the sediment, which stimulates microbial activity. Slower currents can reduce food supply to filter feeders inhabiting the invaded habitat. All these 
processes would normally lead to reduced primary productivity, mainly of microalgae in the sediments (obviously, if the invader is a primary producer, overall ecosystem primary productivity might increase), and the deteriorating conditions can negatively affect metabolic functions (e.g., growth) of many native species.

Pathway 2 - Reduced light (autogenic-allogenic). Many invaders, particularly large or densely packed plants and algae or epiphytes increase the shading of the invaded environment thereby reducing light penetration, leading to lower primary productivity of small native plants (or large ones on which invasive epiphytes grow on), macroalgae and benthic microalgae, and to an increased community respiration. Reduced photosynthesis results in lower food availability for macro- and micro-grazers (those that do not feed on the invader).

Pathway 3 - Increased decomposition (autogenic). Many invasive species decompose more rapidly than their native congeners (Allison \& Vitousek, 2004, Hahn, 2003, Olabarria et al., 2010) which explains the high carbon and nitrogen flux in invaded vs. native ecosystems (Liao et al., 2008). Thus, by rapid decomposition, invasive marine engineers can increase the nutrient flux and sedimentation, which in turn may lead to anaerobic conditions and thus to reduced metabolic functions in the residing native species.

Pathway 4 - Increased 3D structure (autogenic). The addition of substrate for settlement and the amelioration of environmental stress by offering more shelter, particularly in areas where natural complexity is low, increases the number of niches available to local (and invasive) species that require specific habitats, but also potentially reduce available habitat for species that are inhabitants of the original low-complexity habitat.

The complex interactions among all the above pathways change the benthic community whereby some species are facilitated and some are suppressed. The balance 
between the pathways, which depends on the traits of the invader and the native community, will determine which functions are more strongly influenced, and if community abundance and diversity will increase or decrease. There are many secondary indirect pathways that affect community composition once the new substrate (or activity) is introduced by the invader, which operate primarily through species interactions (competition, consumption, facilitation). These biotic interactions add further complexity, making it hard to predict the exact pathways of change for local communities and function. Unfortunately, very few studies meeting the criteria set out by this review focused on the engineering effects of burrowing, or bioturbator species (e.g., crabs, bivalves and worms) that are known to be important allogenic ecosystem engineers. Burrowers remove complexity (Chinese mitten crab destroying estuary banks) or significantly enhance it (e.g., through bioturbation) modifying local functioning (e.g. nutrient cycling, Bertics et al., 2010). It is clear that pathways other than those described above operate in these invasions, and the function and community outcomes may be very different due to bioturbators' strong influence on the ecosystem's geochemistry and diversity (Meysman et al., 2006, Queirós et al., 2013). The effect of only one burrowing species on ecosystem functions was included in this analysis: those of the invasive burrowing polychaete worm, Marenzelleria viridis. The worm was shown to change the metabolism of the benthos by stimulating sulphate reduction at the expense of aerobic respiration (Kristensen et al., 2011), as well as increasing benthic production (chlorophyll $a$ ) due to higher biodeposition and/or bioturbation activity (Kotta et al., 2001, Laverock et al., 2011). As shown by others, the effect of bioturbators in invaded ecosystems can be highly dependent on the local species composition and habitat structure (Queirós et al., 2011).

Two other well-known invader life-forms were very rare in the current analysis: mobile benthic species and pelagic species. The only pelagic species with suggested engineering effects in their broader sense (including direct chemical effects) included in this 
review, was the ctenophore, Mnemiopsis leidyi, in the Caspian Sea, where it increased nutrient levels considerably, possibly due to secretion of mucus (Nasrollahzadeh et al., 2008a, 2008b). The presence of this invader apparently resulted in higher abundance and biodiversity of the phytoplankton community, but these could not be assessed because the variation around the mean was not provided.

In conclusion, this systematic review and meta-analysis revealed the complex and diverse effects of IEE in the marine environment. Regardless of many confounding elements in the present state of knowledge, as expressed in this synthesis, a key finding is that IEE impacts can be strong, but the direction of the impact is highly variable among studies at the biodiversity level and strong and more unidirectional at the functional level. Although the formal analysis did not identify a publication bias, we identified several research-focus biases. One of the problems may lie in the sometimes-diffuse definition of ecosystem engineering, which is highly dependent on scale, and on differing interpretations of the concept. The two concepts encompassed in the phrase 'invasive ecosystem engineering species' produce difficulties to a researcher wishing to explore its ecological meaning and impact. First is the concept of invasive species, presenting several temporal-scale complexities in definition (when does an alien become 'invasive' and when, if ever, it stops being 'alien'). This has been discussed in depth in many studies and reviews (Ruiz \& Carlton, 2003, Shrader-Frechette, 2001, Valéry et al., 2008), with numerous standardization attempts (Hodges, 2008). Second, and far less discussed, is the definition of ecosystem engineers (Jones et al., 1994). It is clear that at small scales most species can act as ecosystem engineers, as they modify the chemical and physical environment through metabolic functions, movement and structure. Therefore, our ability to detect the engineering effects depends on the scale of measurement. Apparently, there is a need for many more studies that look at community and function effects together to make the links between them more 
apparent and the processes involved better understood. Finally, the fact that many ecosystem functions were negatively affected by IEE suggests that ecosystem services may also be affected by the invaders because functions and services are closely linked (Cardinale et al., 2012). This aspect deserves further study and analysis and requires the attention of managers and policy makers.

\section{ACKNOWLEDGMENTS}

This research was funded by the EU Seventh Framework Programme for research, technological development and demonstration (FP7/2007-2013) within the Ocean of Tomorrow call under Grant Agreement No.266445 for the project Vectors of Change in Oceans and Seas Marine Life (VECTORS). We would like to thank the two anonymous reviewers for their constructive suggestions and comments. Many thanks for team members of the Marine Community Ecology Lab (Rilov lab) at IOLR for their help with data extraction, and to the broader VECTORS community, and especially to Melanie Austen, for insightful discussions. AMQ and PJS acknowledge support from the UK Natural Environment Research Council and Department for Environment, Food and Rural Affairs [grant number NE/L003279/1, Marine Ecosystems Research Programme]. HO and JK were partly funded by the Estonian Ministry of Education and Research (grant SF0180005s10) and the Estonian Research Council (IUT02-20).

This article is protected by copyright. All rights reserved. 


\section{References}

Allison SD, Vitousek PM (2004) Rapid nutrient cycling in leaf litter from invasive plants in Hawai'i. Oecologia, 141, 612-619.

Bertics VJ, Sohm JA, Treude T, Chow C-ET, Capone DC, Fuhrman JA, Ziebis W (2010) Burrowing deeper into benthic nitrogen cycling: the impact of bioturbation on nitrogen fixation coupled to sulfate reduction. Marine Ecology Progress Series, 409, $1-15$.

Bertness MD, Callaway R (1994) Positive interactions in communities. Trends in Ecology \& Evolution, 9, 191-193.

Borenstein M, Hedges L, Higgins J, Rothstein H (2005) Comprehensive meta-analysis (ed Englewood N), Biostat.

Borenstein M, Hedges LV, Higgins JP, Rothstein HR (2011) Introduction to meta-analysis, Wiley.

Bos AR, Bouma TJ, De Kort GL, Van Katwijk MM (2007) Ecosystem engineering by annual intertidal seagrass beds: sediment accretion and modification. Estuarine, Coastal and Shelf Science, 74, 344-348.

Bouma T, De Vries M, Low E, Peralta G, Tánczos I, Van De Koppel J, Herman PMJ (2005) Trade-offs related to ecosystem engineering: a case study on stiffness of emerging macrophytes. Ecology, 86, 2187-2199.

Bruno JF, Stachowicz JJ, Bertness MD (2003) Inclusion of facilitation into ecological theory. Trends in Ecology \& Evolution, 18, 119-125.

Byers JE, Cuddington K, Jones CG et al. (2006) Using ecosystem engineers to restore ecological systems. Trends in Ecology \& Evolution, 21, 493-500.Cardinale BJ, Duffy JE, Gonzalez A et al. (2012) Biodiversity loss and its impact on humanity. Nature, 486, 59-67.

Coll M, Piroddi C, Steenbeek J et al. (2010) The biodiversity of the Mediterranean Sea: estimates, patterns, and threats. PloS one, 5, 11842.

Connolly J, Bell T, Bolger T et al. (2013) An improved model to predict the effects of changing biodiversity levels on ecosystem function. Journal of Ecology, 101, 344355.

Crooks J (2009) The Role of Exotic Marine Ecosystem Engineers. In: Biological Invasions in Marine Ecosystems: Ecological, Management, and Geographic Perspectives. (eds Rilov G, Crook A), Springer.

Crooks JA (1998) Habitat alteration and community-level effects of an exotic mussel, Musculista senhousia. Marine Ecology-Progress Series, 162, 137-152.

Crooks JA (2002) Characterizing ecosystem-level consequences of biological invasions: the role of ecosystem engineers. Oikos, 97, 153-166.

Demopoulos AWJ, Smith CR (2010) Invasive mangroves alter macrofaunal community structure and facilitate opportunistic exotics. Marine Ecology Progress Series, 404, 51-67.

Deudero S, Blanco A, Box A, Mateu-Vicens G, Cabanellas-Reboredo M, Sureda A (2010) Interaction between the invasive macroalga Lophocladia lallemandii and the bryozoan Reteporella grimaldii at seagrass meadows: density and physiological responses. Biological Invasions, 12, 41-52.

Duval S, Tweedie R (2000) A simple funnel-plot-based method of testing and adjusting for publication bias in meta-analysis. Biometrics, 56, 455-463.

Ehrenfeld JG (2010) Ecosystem consequences of biological invasions. Annual review of ecology, evolution, and systematics, 41, 59-80.

This article is protected by copyright. All rights reserved. 
Gamfeldt L, Snäll T, Bagchi R et al. (2013) Higher levels of multiple ecosystem services are found in forests with more tree species. Nature communications, 4, 1340.

Grosholz ED, Ruiz GM (2009) Multitrophic Effects of Invasions in Marine and Estuarine Systems. In: Biological Invasions in Marine Ecosystems: Ecological, Management, and Geographic Perspectives. (eds Rilov G, Crooks JA). Berlin Heidelberg, Springer

Hahn DR (2003) Alteration of microbial community composition and changes in decomposition associated with an invasive intertidal macrophyte. In: Marine Bioinvasions: Patterns, Processes and Perspectives. Springer.

Harlin MM, Villalard-Bohnsack M (2001) Seasonal dynamics and recruitment strategies of the invasive seaweed Grateloupia doryphora (Halymeniaceae, Rhodophyta) in Narragansett Bay and Rhode Island Sound, Rhode Island, USA. Phycologia, 40, 468474.

Hastings A, Byers JE, Crooks JA et al. (2007) Ecosystem engineering in space and time. Ecology Letters, 10, 153-164.

Hedges LV (1981) Distribution theory for Glass's estimator of effect size and related estimators. Journal of Educational and Behavioral Statistics, 6, 107-128.

Higgins SN, Vander Zanden MJ (2010) What a difference a species makes: a meta-analysis of dreissenid mussel impacts on freshwater ecosystems. Ecological Monographs, 80, 179-196.

Hodges KE (2008) Defining the problem: terminology and progress in ecology. Frontiers in Ecology and the Environment, 6, 35-42.

Höffle H, Thomsen MS, Holmer M (2011) High mortality of Zostera marina under high temperature regimes but minor effects of the invasive macroalgae Gracilaria vermiculophylla. Estuarine, Coastal and Shelf Science, 92, 35-46.

Holmer M, Marba N, Lamote M, Duarte CM (2009) Deterioration of sediment quality in seagrass meadows (Posidonia oceanica) invaded by macroalgae (Caulerpa sp.). Estuaries and Coasts, 32, 456-466.

Hooper DU, Chapin FS, Ewel JJ et al. (2005) Effects of biodiversity on ecosystem functioning: A consensus of current knowledge. Ecological Monographs, 75, 3-35.

Hulme PE, Pyšek P, Jarošík V, Pergl J, Schaffner U, Vila M (2013) Bias and error in understanding plant invasion impacts. Trends in Ecology \& Evolution, 28, 212-218.

Jones C, Gutierrez J, Byers J, Crooks J, Lambrinos J, Talley T (2010) A framework for understanding physical ecosystem engineering by organisms. Oikos, 119, 1862 1869.

Jones CG, Lawton JH, Shachak M (1994) Organisms as Ecosystem Engineers. Oikos, 69, 373-386.

Jones CG, Lawton JH, Shachak M (1997) Positive and negative effects of organisms as physical ecosystem engineers. Ecology, 78, 1946-1957.

Kideys AE (2002) Fall and rise of the Black Sea ecosystem. Science, 297, 1482-1484.

Kotta J, Orav H, Sandberg-Kilpi E (2001) Ecological consequence of the introduction of the polychaete Marenzelleria viridis into a shallow-water biotope of the northern Baltic Sea. Journal of Sea Research, 46, 273-280.

Kotta J, Herkül K, Kotta I, Orav-Kotta H, Lauringson V (2009) Effects of the suspension feeding mussel Mytilus trossulus on a brackish water macroalgal and associated invertebrate community. Marine Ecology, 30, 56-64.

Kremen C (2005) Managing ecosystem services: what do we need to know about their ecology? Ecology Letters, 8, 468-479.

Kristensen E, Hansen T, Delefosse M, Banta GT, Quintana CO (2011) Contrasting effects of the polychaetes Marenzelleria viridis and Nereis diversicolor on benthic metabolism

This article is protected by copyright. All rights reserved. 
and solute transport in sandy coastal sediment. Marine Ecology Progress Series, 425, 125-139.

Laverock B, Gilbert J, Tait K, Osborn AM, Widdicombe S (2011) Bioturbation: impact on the marine nitrogen cycle. Biochemical Society Transactions, 39, 315.

Lejart M, Hily C (2011) Differential response of benthic macrofauna to the formation of novel oyster reefs (Crassostrea giga, Thunberg) on soft and rocky substrate in the intertidal of the Bay of Brest, France. Journal of Sea Research, 65, 84-93.

Liao C, Peng R, Luo Y, Zhou X, Wu X, Fang C, Chen J, Li B (2008) Altered ecosystem carbon and nitrogen cycles by plant invasion: A meta-analysis. New phytologist, 177, 706-714.

Lipsey M, Wilson D (2001) Applied social research methods series: Vol. 49. Practical metaanalysis. , London: Sage Publications.

Loreau M, Mazancourt C (2013) Biodiversity and ecosystem stability: a synthesis of underlying mechanisms. Ecology Letters, 16, 106-115.

Loreau M, Naeem S, Inchausti P et al. (2001) Ecology - Biodiversity and ecosystem functioning: Current knowledge and future challenges. Science, 294, 804-808.

Lorenti M, Gambi MC, Guglielmo R, Patti FP, Scipione MB, Zupo V, Buia MC (2011) Soft-bottom macrofaunal assemblages in the Gulf of Salerno, Tyrrhenian Sea, Italy, an area affected by the invasion of the seaweed Caulerpa racemosa var. cylindracea. Marine Ecology, 32, 320-334.

Maggi E, Benedetti-Cecchi L, Castelli A, Chatzinikolaou E, Crowe TP, Ghedini G, Kotta J, Lyons DA, Ravaglioli C, Rilov G, Rindi L (2015) Ecological impacts of invading seaweeds: a meta-analysis of their effects at different trophic levels. Diversity and Distributions, 21, 1-12.

Marras S, Cucco A, Antognarelli F, Azzurro E, Milazzo M, Bariche M, Butenschön M, Kay S, Di Bitetto M, Quattrocchi G, Sinerchia M, Domenici P (2015) Predicting future thermal habitat suitability of competing native and invasive fish species: from metabolic scope to oceanographic modelling. Conservation physiology, $\mathbf{3}, 1$.

Martin LJ, Blossey B, Ellis E (2012) Mapping where ecologists work: biases in the global distribution of terrestrial ecological observations. Frontiers in Ecology and the Environment, 10, 195-201.

Martin S, Thouzeau G, Richard M, Chauvaud L, Jean F, Clavier J (2007) Benthic community respiration in areas impacted by the invasive mollusk Crepidula fornicata. Marine Ecology Progress Series, 347, 51-60.

Matsuzaki SS, Usio N, Takamura N, Washitani I (2009) Contrasting impacts of invasive engineers on freshwater ecosystems: an experiment and meta-analysis. Oecologia, 158, 673-686.

Meinesz A, Belsher T, Thibaut T, Antolic B, Mustapha KB, Boudouresque CF, Chiaverini D, Cinelli F, Cottalorda JM, Djellouli A, El Abed A (2001) The introduced green alga Caulerpa taxifolia continues to spread in the Mediterranean. Biological invasions, $\mathbf{3}$, 201-210.

Meysman FJ, Middelburg JJ, Heip CH (2006) Bioturbation: a fresh look at Darwin's last idea. Trends in Ecology \& Evolution, 21, 688-695.

Molnar JL, Gamboa RL, Revenga C, Spalding MD (2008) Assessing the global threat of invasive species to marine biodiversity. Frontiers in Ecology and the Environment, 6, 485-492.

Mooney H, Hobbs R (2000) Invasive Species in a Changing World, Island Press, Washington.

Mouillot D, Villéger S, Scherer-Lorenzen M, Mason NW (2011) Functional structure of biological communities predicts ecosystem multifunctionality. PloS one, 6, e17476.

This article is protected by copyright. All rights reserved. 
Mouillot D, Bellwood DR, Baraloto C et al. (2013) Rare species support vulnerable functions in high-diversity ecosystems. PLoS Biology, 11, e1001569.

Nasrollahzadeh H, Din Z, Foong S, Makhlough A (2008a) Spatial and temporal distribution of macronutrients and phytoplankton before and after the invasion of the ctenophore, Mnemiopsis leidyi, in the Southern Caspian Sea. Chemistry and Ecology, 24, 233246.

Nasrollahzadeh HS, Din ZB, Foong SY, Makhlough A (2008b) Trophic status of the Iranian Caspian Sea based on water quality parameters and phytoplankton diversity. Continental Shelf Research, 28, 1153-1165.

Neira C, Levin LA, Grosholz ED (2005) Benthic macrofaunal communities of three sites in San Francisco Bay invaded by hybrid Spartina, with comparison to uninvaded habitats. Marine Ecology-Progress Series, 292, 111-126.

Neira C, Levin LA, Grosholz ED, Mendoza G (2007) Influence of invasive Spartina growth stages on associated macrofaunal communities. Biological Invasions, 9, 975-993.

Nyström P, Svensson O, Lardner B, Brönmark C, Granéli W (2001) The influence of multiple introduced predators on a littoral pond community. Ecology, 82, 1023-1039.

Olabarria C, Incera M, Garrido J, Rossi F (2010) The effect of wrack composition and diversity on macrofaunal assemblages in intertidal marine sediments. Journal of Experimental Marine Biology and Ecology, 396, 18-26.

Primack R (1995) A primer of conservation biology, Sunderland, Massachusetts, Sinauer.

Pyšek P (1995) On the terminology used in plant invasion studies. Plant invasions: general aspects and special problems, 71-81.

Pyšek P, Richardson DM, Pergl J, Jarošík V, Sixtová Z, Weber E (2008) Geographical and taxonomic biases in invasion ecology. Trends in ecology \& evolution, 23, 237-244.

Pyšek P, Jarošík V, Hulme PE, Pergl J, Hejda M, Schaffner U, Vilà M (2012) A global assessment of invasive plant impacts on resident species, communities and ecosystems: the interaction of impact measures, invading species' traits and environment. Global Change Biology, 18, 1725-1737.

Queirós AM, Birchenough SN, Bremner J et al. (2013) A bioturbation classification of European marine infaunal invertebrates. Ecology and evolution, 3, 3958-3985.

Queirós AM, Hiddink JG, Johnson G, Cabral HN, Kaiser MJ (2011) Context dependence of marine ecosystem engineer invasion impacts on benthic ecosystem functioning. Biological Invasions, 13, 1059-1075.

Rilov G (2009) Predator-prey interactions in marine bioinvasions. In: Biological Invasions in Marine Ecosystems: Ecological, Management, and Geographic Perspectives. (eds Rilov G, Crooks JA). Heidelberg, Germany, Springer.

Rilov G, Crooks JA (2009) Biological invasions in marine ecosystems: ecological, management, and geographic perspectives, Springer.

Rilov G, Mant R, Lyons D et al. (2012) How strong is the effect of invasive ecosystem engineers on the distribution patterns of local species, the local and regional biodiversity and ecosystem functions? Environmental Evidence, 1, 10.

Rodriguez LF (2006) Can invasive species facilitate native species? Evidence of how, when, and why these impacts occur. Biological Invasions, 8, 927-939.

Romero GQ, Gonçalves-Souza T, Vieira C, Koricheva J (2015) Ecosystem engineering effects on species diversity across ecosystems: a meta-analysis. Biological Reviews, 90, 877-890.

Ruiz G, Carlton J (2003) Invasive species: vectors and management strategies, Island Press.

Sax, DF (2001) Latitudinal gradients and geographic ranges of exotic species: implications for biogeography. Journal of Biogeography, 28, 139-150.

This article is protected by copyright. All rights reserved. 
Schemske DW, Mittelbach GG, Cornell HV, Sobel JM, Roy K (2009) Is there a latitudinal gradient in the importance of biotic interactions? Annual Review of Ecology, Evolution, and Systematics, 40, 245-269.

Schwartz M, Brigham C, Hoeksema J, Lyons K, Mills M, Van Mantgem P (2000) Linking biodiversity to ecosystem function: implications for conservation ecology. Oecologia, 122, 297-305.

Sherman K, Hempel G (2009) The UNEP Large Marine Ecosystem Report: A perspective on changing conditions in LMEs of the world's Regional Seas. UNEP Regional Seas Reports and Studies, 182.

Shiganova TA, Bulgakova YV (2000) Effects of gelatinous plankton on Black Sea and Sea of Azov fish and their food resources. ICES Journal of Marine Science, 57, 641-648.

Shrader-Frechette K (2001) Non-indigenous species and ecological explanation. Biology and Philosophy, 16, 507-519.

Simberloff D (2011) How common are invasion-induced ecosystem impacts? Biological Invasions, 13, 1255-1268.

Simberloff D, B Von Holle. 1999. Positive interactions of nonindigenous species: invasional meltdown? Biological invasions 1, 21-32.

Stachowicz JJ (2001) Mutualism, facilitation, and the structure of ecological communities. BioScience 51, 235-246.

Strayer DL (2012) Eight questions about invasions and ecosystem functioning. Ecology Letters, 15, 1199-1210.

Strayer DL, Eviner VT, Jeschke JM, Pace ML (2006) Understanding the long-term effects of species invasions. Trends in Ecology \& Evolution, 21, 645-651.

Sureda A, Box A, Terrados J, Deudero S, Pons A (2008) Antioxidant response of the seagrass Posidonia oceanica when epiphytized by the invasive macroalgae Lophocladia lallemandii. Marine Environmental Research, 66, 359-363.

Thomsen MS, Wernberg T, Olden JD, Byers JE, Bruno JF, Silliman BR, Schiel DR (2014) Forty years of experiments on aquatic invasive species: are study biases limiting our understanding of impacts. NeoBiota, 22, 1-22.

Valéry L, Fritz H, Lefeuvre J-C, Simberloff D (2008) In search of a real definition of the biological invasion phenomenon itself. Biological Invasions, 10, 1345-1351.

Vilà M, Espinar JL, Hejda M, Hulme PE, Jarošík V, Maron JL, Pergl J, Schaffner U, Sun Y, Pyšek P (2011) Ecological impacts of invasive alien plants: a meta-analysis of their effects on species, communities and ecosystems. Ecology Letters 14, 702-708.

Wolak ME, Fairbairn DJ, Paulsen YR (2012) Guidelines for estimating repeatability. Methods in Ecology and Evolution, 3, 129-137.

Zavaleta ES, Pasari JR, Hulvey KB, Tilman GD (2010) Sustaining multiple ecosystem functions in grassland communities requires higher biodiversity. Proceedings of the National Academy of Sciences, 107, 1443-1446.

This article is protected by copyright. All rights reserved. 


\section{FIGURE CAPTIONS}

Figure 1. The number of ecosystem engineer publications* (blue line, left y-axis) and the number of invasive ecosystem engineers (IEE) used in this paper (empty circles, right y-axis) between 1990-2016. *based on the number of search hits in Scopus and ISI Web of Science.

Figure 2. The taxonomic representation of IEE and the studied habitat types in the complete meta-analysis dataset $(n=385)$.

Figure 3. Study distribution among the large marine ecosystems of the world (Sherman \& Hempel, 2009). The number of studies performed in the regions, divided among the 66 marine ecosystems, is coloured according to the map scale. The largest amount of studies $(15 \%)$ was performed in the Mediterranean Sea.

Figure 4. The overall summary effects of 10 response (outcome) categories (Hedges' $\mathrm{g} \pm$ 95\% C.I.) as inferred from random-effects model meta-analyses. Sample size (n) and p-value are presented above the horizontal bars of each outcome. Outcome categories that concern species and community abundance and diversity are represented by green triangles. Outcome categories that concern ecosystem functions are represented by red circles.

Figure 5. Subgroup results from all response categories where significant effect of at least one subgroup within the analysis was detected. The subgroups are represented by circles, and the overall effect size (Hedges' $\mathrm{g} \pm 95 \%$ C.I.) is represented by a square symbol and a dashed line. The solid line denotes zero. Sample size (n) in each subgroup is on the right side of the confidence interval. To compute the overall effect size a mixed-effects model was used. A random effects model was used to combine studies within each subgroup. The following subgroups per outcome are presented: Single species - (a) habitat type, (b) region; Community abundance - (c) engineering type, (d) IEE taxonomic group, (e) region; Species richness - (f) IEE taxonomic group, (g) habitat type, (h) region; Species diversity - (i) habitat type, (j) region; Primary production - (k) IEE taxonomic group; Sedimentation rate - (l) study type, (m) habitat, (n) region, (o) IEE taxonomic group; Nutrient flux - (p) nutrient type, (q) engineering type, (r) habitat type, (s) IEE taxonomic group, (t) region; Growth and metabolic functions - (u) study type, (v) habitat type, (w) IEE taxonomic group.

Figure 6. Forest plot detailing effect sizes of invasive Spartina on the abundance of single species and taxonomic groups based on data published in Neira et al. (2007). This data exemplifies the high variability of effect sizes, varying between species and experiments, thus possibly obscuring valuable information when summarizing single effects into one overall effect size. Pairs of the following zones were compared: invaded plot $v s$. an adjacent postinvasion (dieback) plot (experiment 1), mature plot vs. a plot in which all Spartina canopy was clipped and removed (experiment 2), mature plot $v s$. un-invaded plot (experiment $3 \mathrm{a}$ ), and an invaded plot with progressed Spartina community (mature) vs. a dieback plot (experiment 3b). Different local taxa within the same experiment showed effect sizes of different strength and direction.

This article is protected by copyright. All rights reserved. 
Figure 7. A conceptual model suggesting four pathways (numbered in the arrows delineated by double lines) through which invasive ecosystem engineers (mainly primary producers and sessile invertebrates with complex 3D structure) may affect ecosystem functions tested in this review and the ecological community. The direction of the white arrows indicate an increase (up) or decrease (down). The black arrows interconnect the pathways. A description of the model is in the text.

\section{SUPPORTING INFORMATION CAPTION}

The supporting information includes six appendices: (1) Search terms used to find relevant studies, (2) Formulas for calculating the Hedges's g effect size, (3) Criteria for exclusion at the full-text level and list of publications included in the meta-analysis, (4) The number of effects in each category of the 81 papers used in the meta-analysis, (5) A detailed description of the studies distribution among categories, (6) Supporting figures that included the full results of the meta-analysis.

This article is protected by copyright. All rights reserved. 

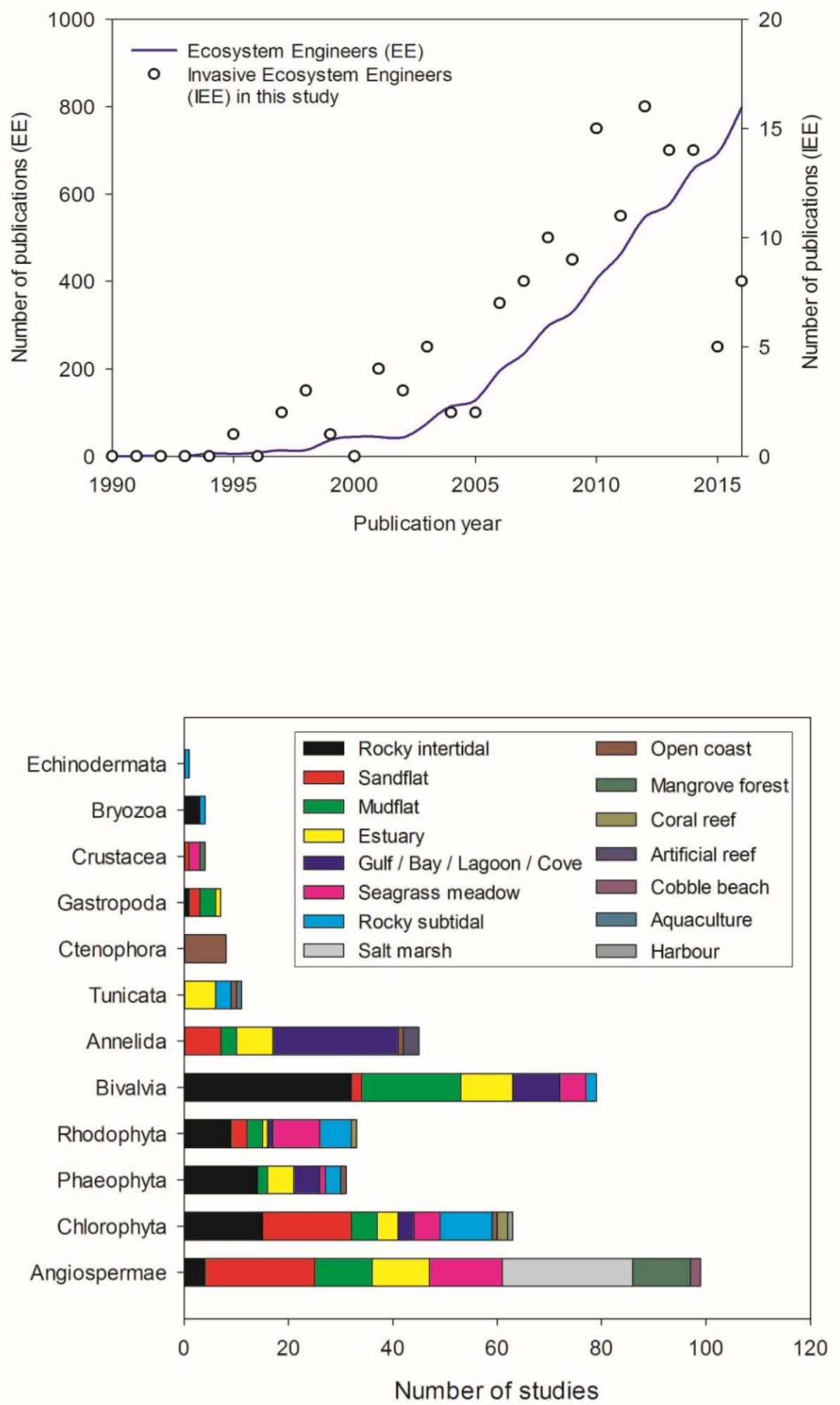

This article is protected by copyright. All rights reserved. 

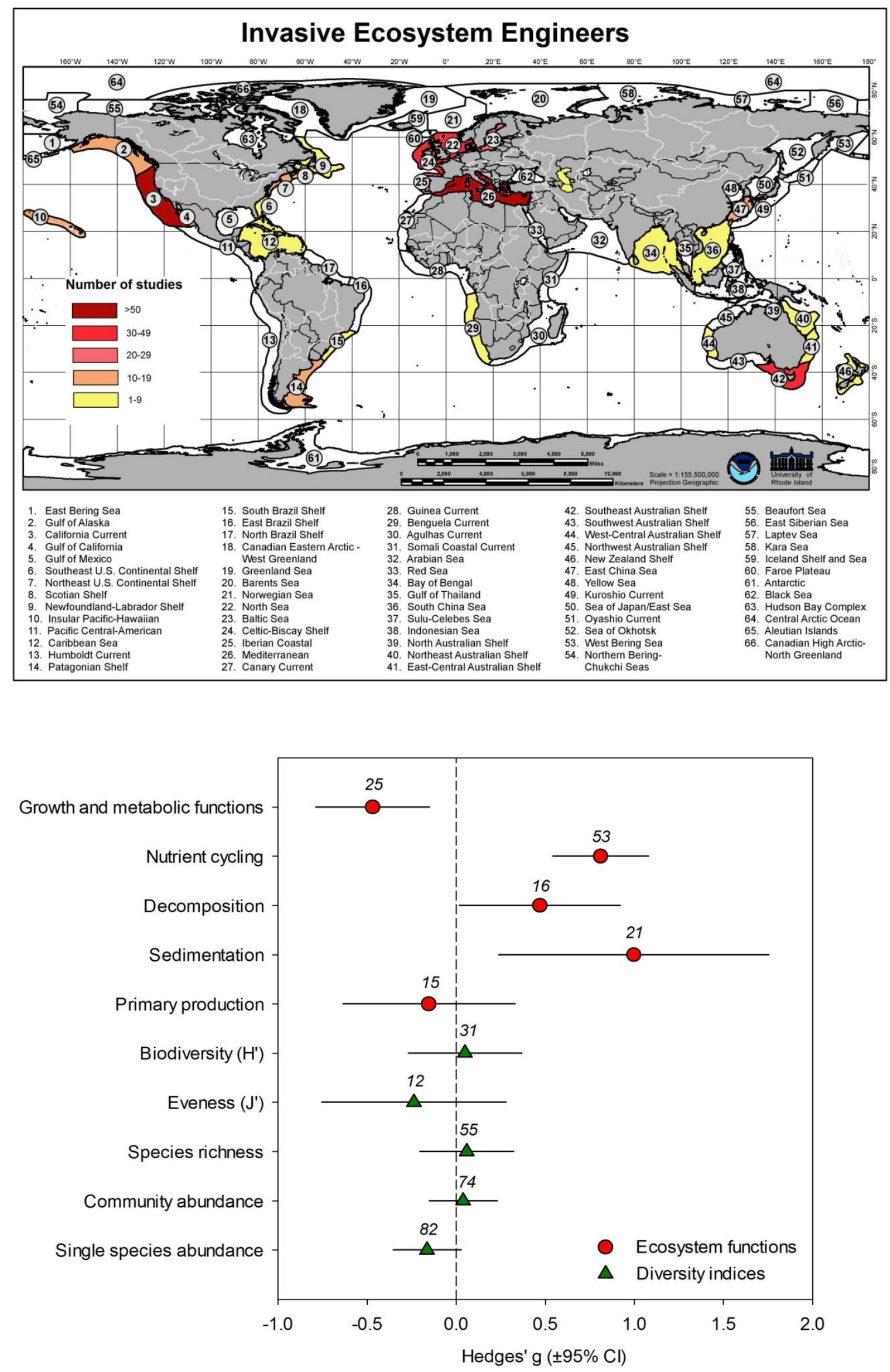

This article is protected by copyright. All rights reserved. 

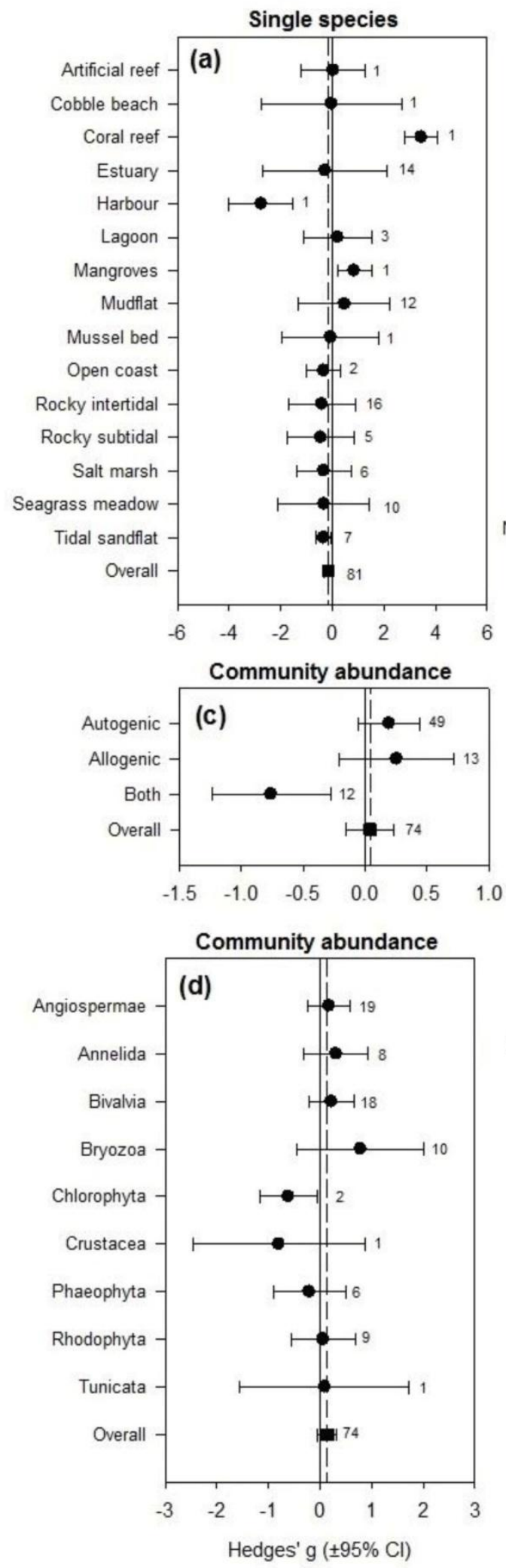
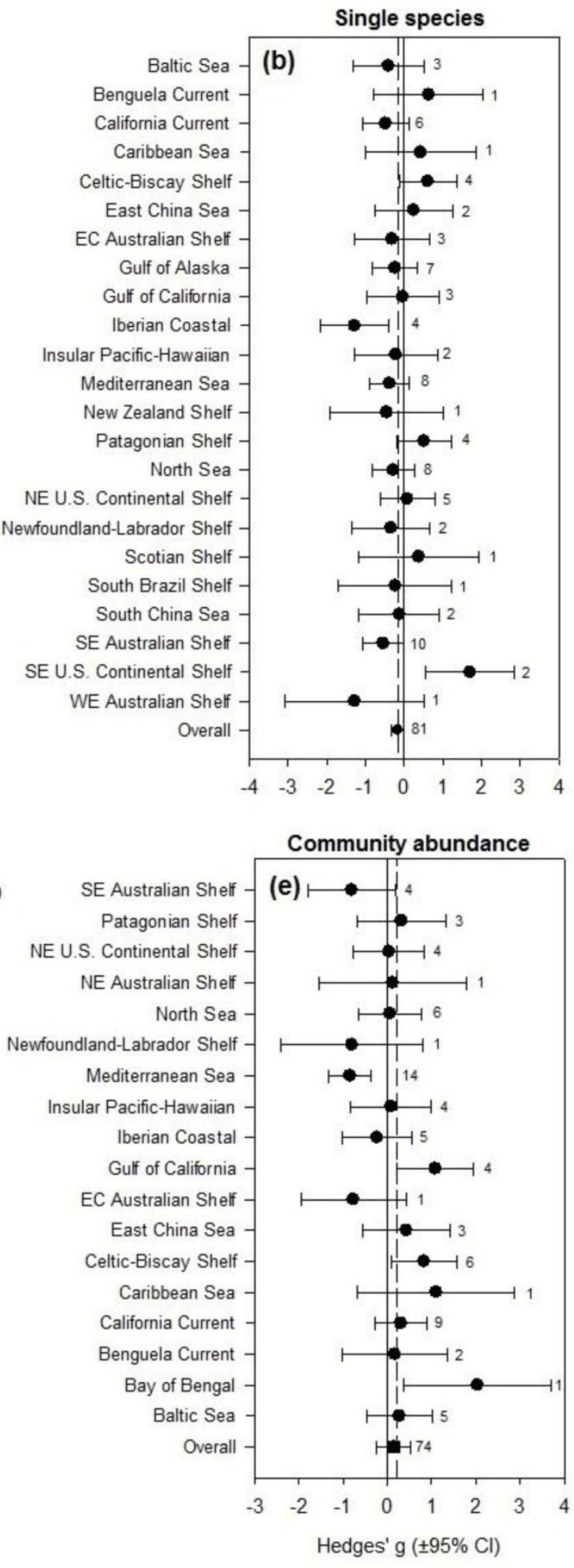

This article is protected by copyright. All rights reserved. 

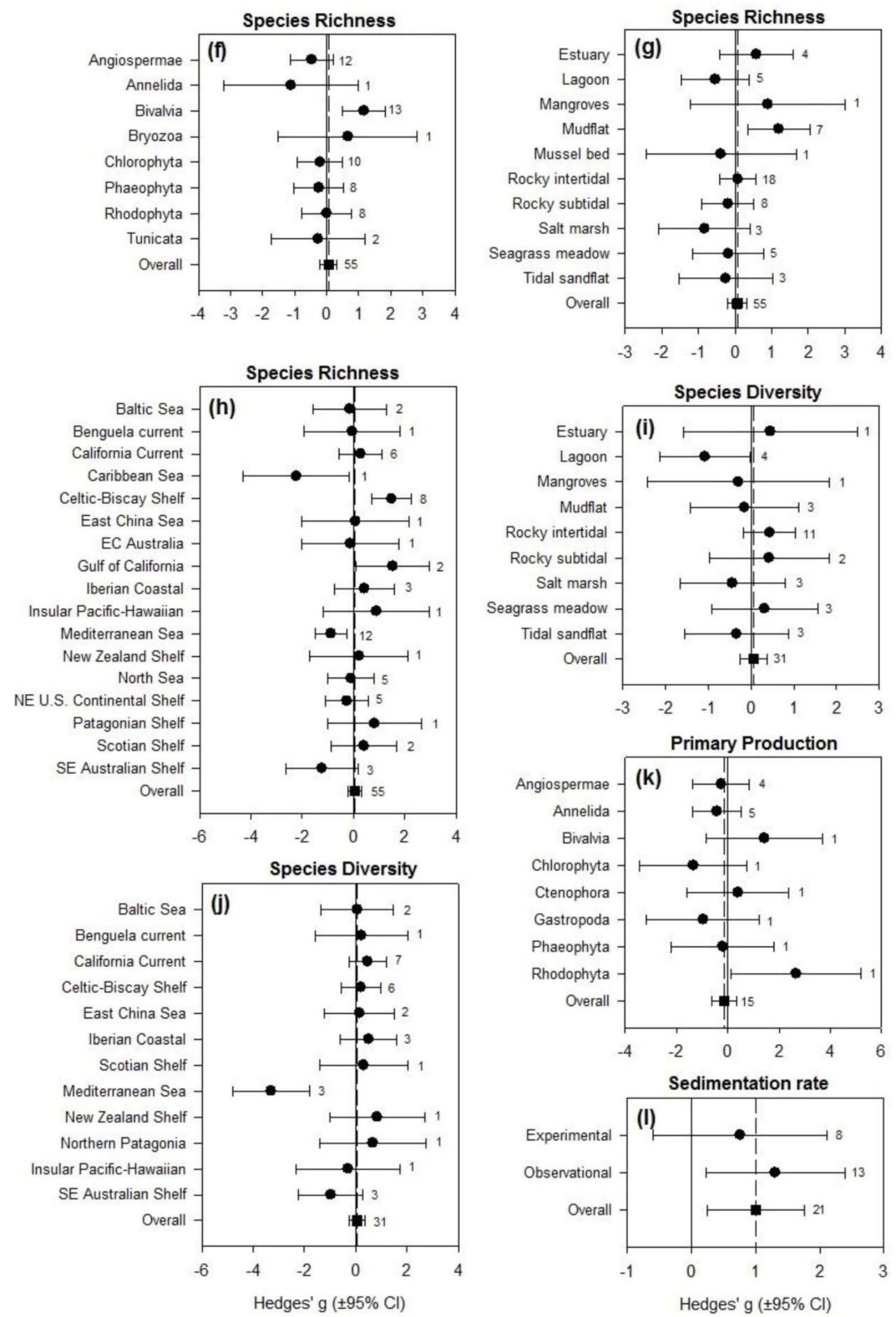

This article is protected by copyright. All rights reserved. 

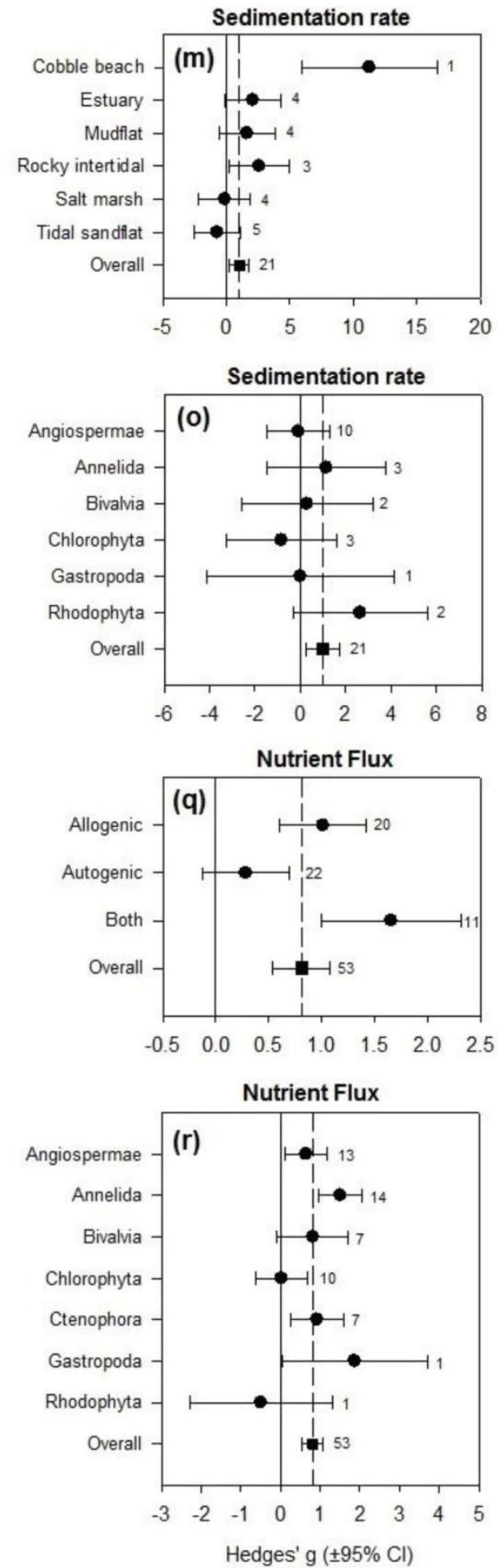
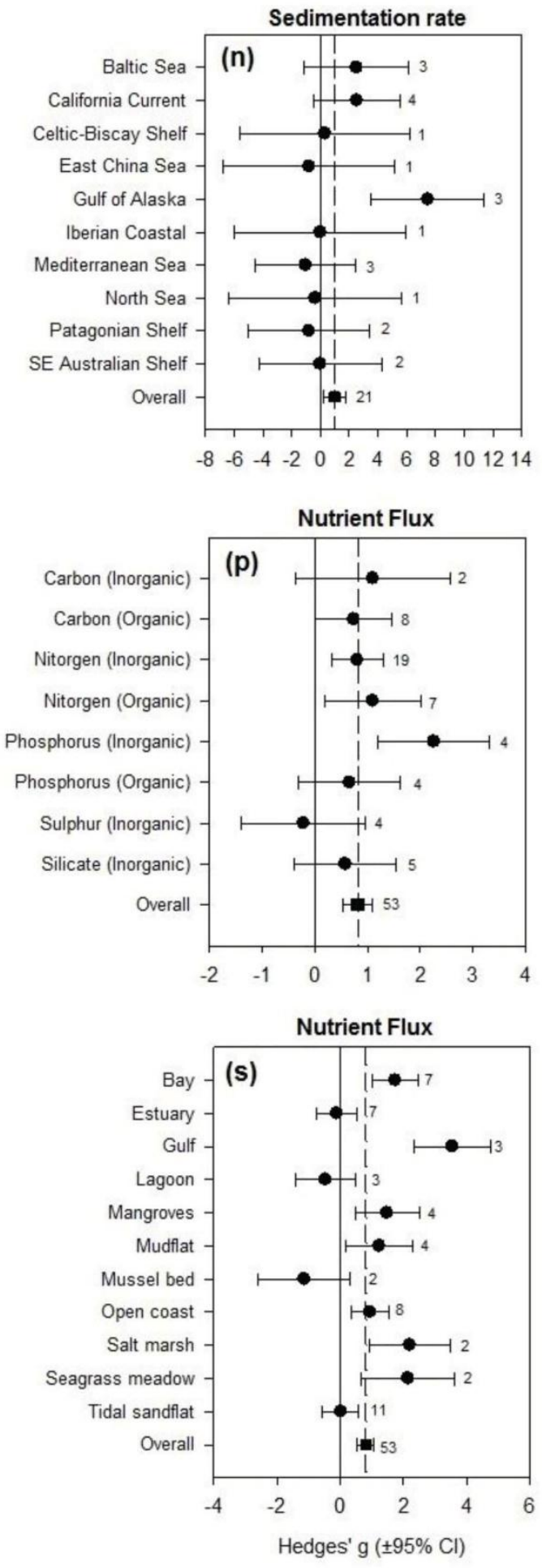

This article is protected by copyright. All rights reserved. 

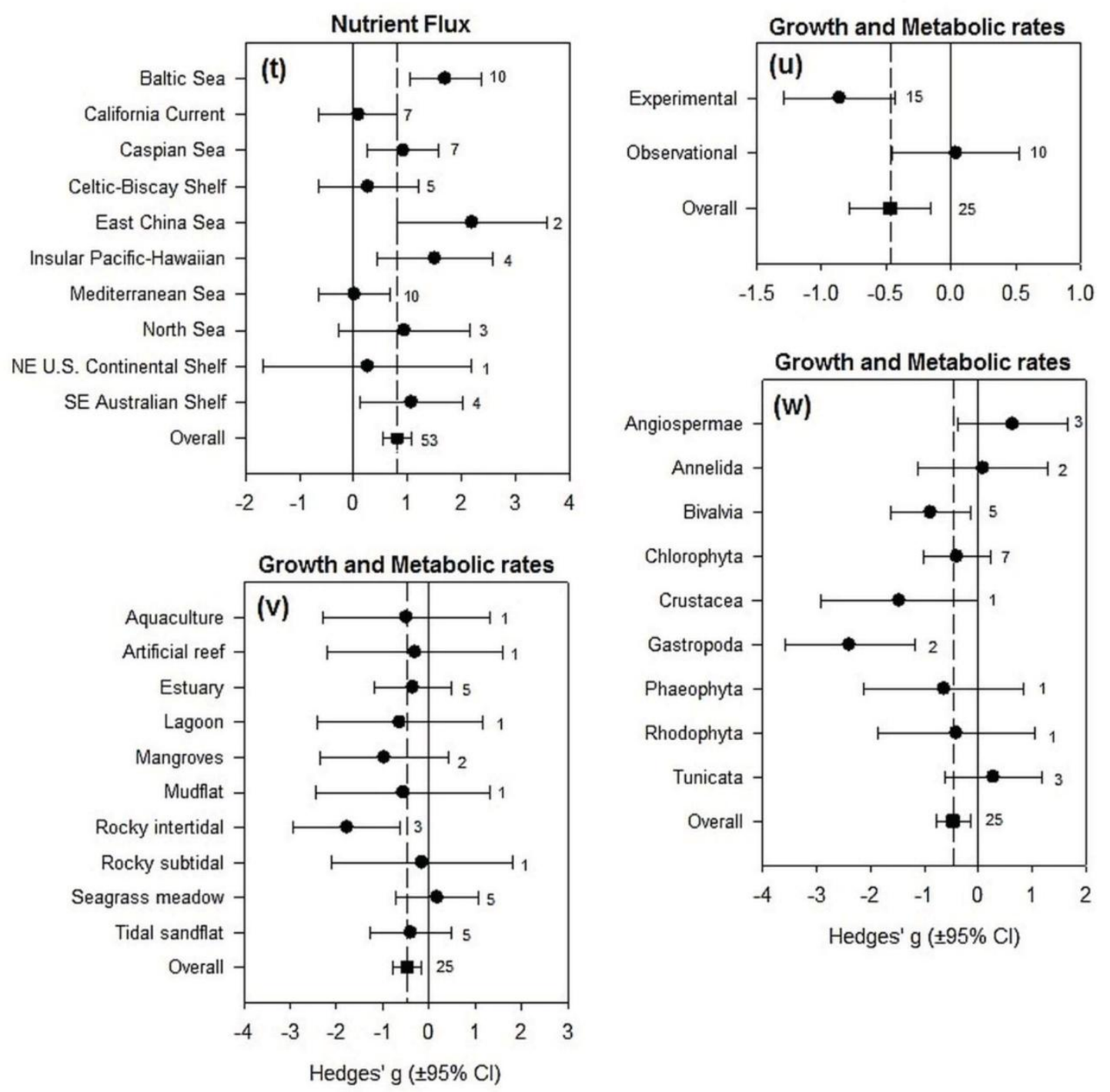

This article is protected by copyright. All rights reserved. 


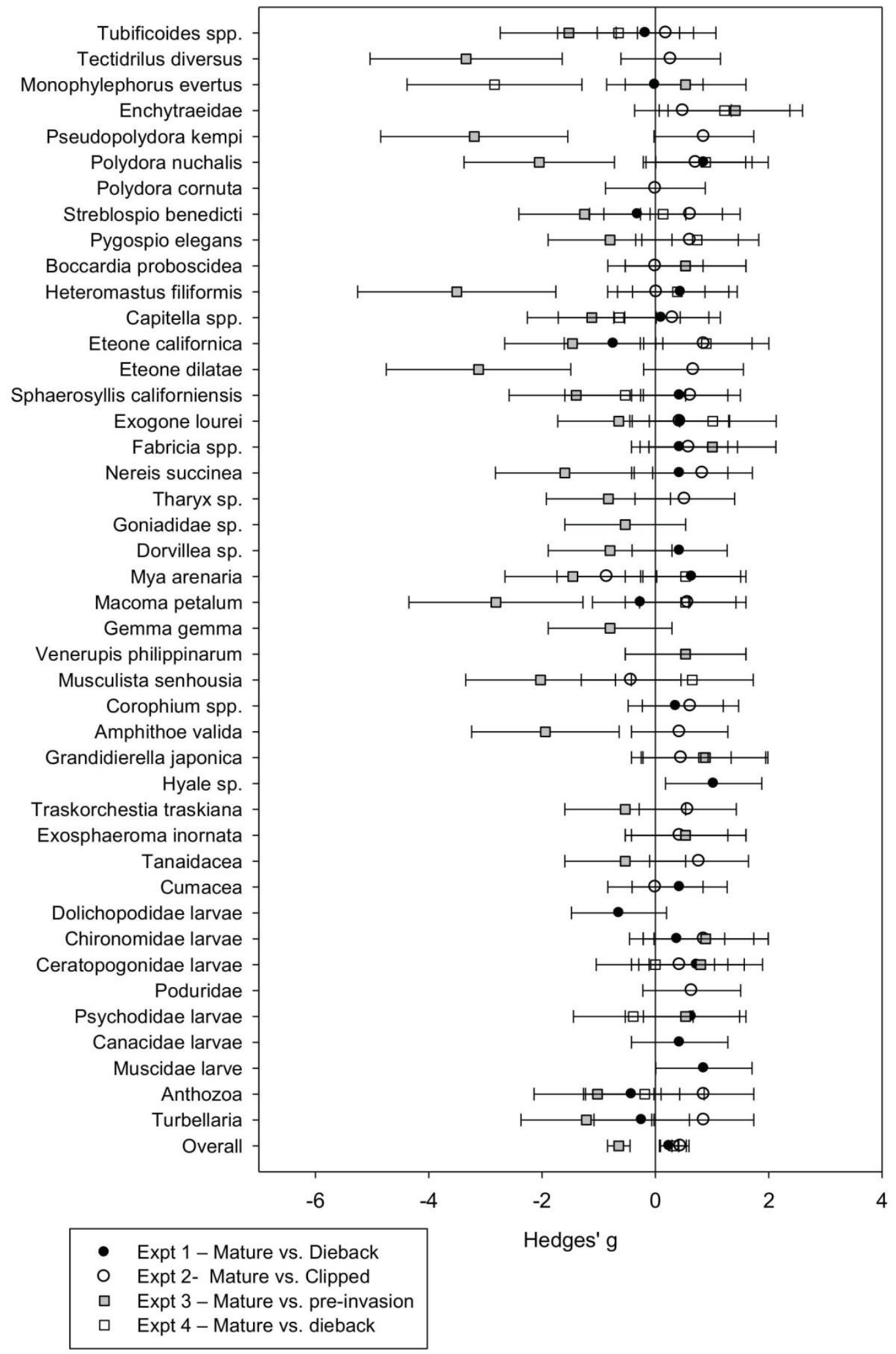

This article is protected by copyright. All rights reserved. 


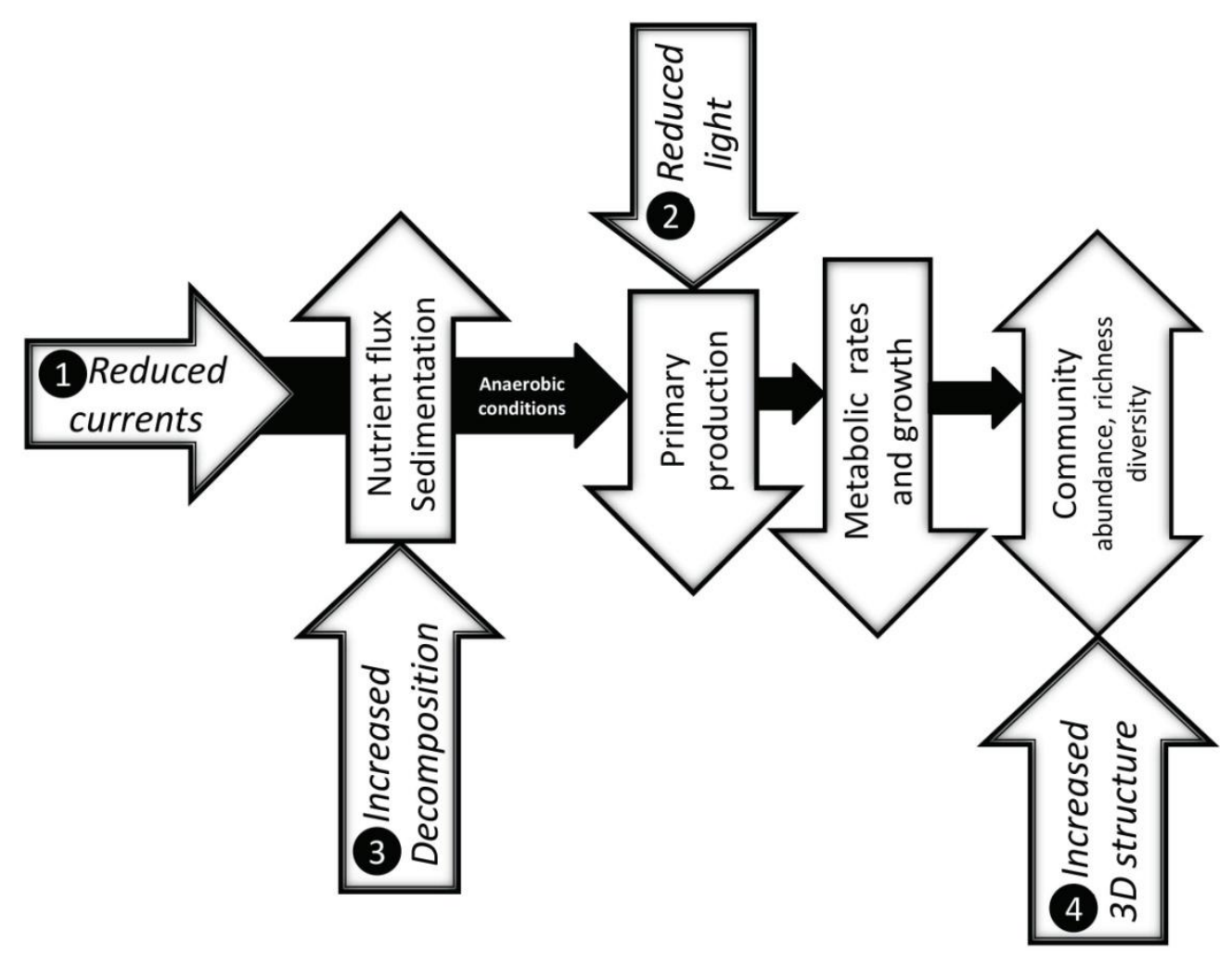

This article is protected by copyright. All rights reserved. 